\title{
Introduction
}

\section{Professor Lance Thomas's 70th Birthday}

\author{
G. Vaughan \\ Physics Department, University of Wales, Aberystwyth, UK
}

On the 4th August Lance Thomas celebrates his seventieth birthday after almost 50 years of research in solar terrestrial Physics. After education at Port Talbot Grammar School he entered the University College of Wales at Swansea to read for a degree in Metallurgy. However, his interests were in the more basic sciences and he transferred to Physics and Mathematics after one year and graduated with an Honours degree in Physics in 1950. He then joined the Ionospheric Research Group headed by Sir Granville Beynon to carry out spaced ionosonde measurements of ionospheric F-region movements and was awarded the Ph.D degree in 1953. After National Service and a post-doctoral fellowship, he was appointed to the staff of the Radio Research Station, later the Appleton Laboratory, at Slough in 1959. In 1981 he moved to the University College of Wales at Aberystwyth as Professor and Head of the Department of Physics until the end of 1994 when he was appointed on a one-third basis as Research Professor.

In his early work at the Radio Research Station, Lance used the extensive data to study the effects of magnetic storms in the $\mathrm{F}$ region, the winter anomaly in radio wave absorption, and lower ionospheric changes associated with aurorae. His subsequent modelling studies of the ionospheric D region, demonstrated its marked temperature dependence arising out of the ion chemistry and examined the effects of solar flares and eclipses. These lower ionosphere studies required parallel treatments of the neutral composition of the mesosphere and lower thermosphere, which led to a study of sodium layer at these heights.

He gained a renewed interest in experimental work in 1970 when he became responsible for the development and use of lidar techniques for observations of atmospheric structure and composition up to about $100 \mathrm{~km}$, and rocket studies of the $\mathrm{D}$ region and mesospheric airglow emissions. The use of tuned dye lasers in lidar systems provided the first evidence of a horizontal variation of the mesospheric sodium layer, with the associated measurement of the $\mathrm{D}_{2}$ line profile providing the basis for the standard lidar method of measuring mesospheric temperatures. The observation of the differential absorption of two ultra-violet wavelengths by ozone provided a measurement of the height profile of this gas and this has also become the accepted lidar method for this measurement. New applications of lidar techniques at Aberystwyth included the observation of gravity waves at stratospheric heights; the presence of ice crystals at $52{ }^{\circ} \mathrm{N}$ in association with noctilucent clouds; the enhancements of stratospheric aerosols following volcanic eruptions; and the height distribution ice crystals associated with cirrus clouds.

In 1980, Lance proposed the establishment of a MST radar system as a UK facility, for which he was appointed Principal Investigator in 1981. With the siting of this radar near Aberystwyth his aim of having adjacent MST and lidar facilities operating simultaneously was fulfilled. His own work on waves with these facilities has included the characteristics of mountain waves and inertia-gravity waves, observations of turbulence associated with critical layers for mountain waves, and enhanced turbulent radio scatter from upper mesospheric heights in summer and its association with low temperatures and ice crystals observed with lidar.

It is evident that Lance's research interests have been very wide ranging. They have moved progressively downwards from his early work in the $F$ region of the ionosphere to the $\mathrm{D}$ region and mesosphere and, between the tropopause to atmospheric waves and turbulence and $100 \mathrm{~km}$. In all these areas he established a high international reputation for innovative work of very high quality, recognized in 1991 by the award of the Charles Chree Medal and Prize by the UK Institute of Physics. Lance also played a substantial part in the management of research programmes through his membership of national and international scientific committees.

The present volume reflects the breadth of Lance's contribution to science, with subjects ranging from the F-region ionosphere down to the tropopause. The first three papers review areas to which Lance has made particular contributions, with the remainder being novel contributions covering the scientific remit of his work. We wish Lance a very happy 70th birthday and a long and prosperous retirement. 